\title{
Do Health, Environmental and Ethical Concerns Affect Purchasing Behavior? A Meta-Analysis and Narrative Review
}

\author{
Wan Nie ${ }^{1}$, Antonieta Medina-Lara ${ }^{1}$, Hywel Williams ${ }^{2,3}$ and Richard Smith ${ }^{1, *}$ \\ 1 Exeter Medical School, University of Exeter, Exeter EX1 2LU, UK; niewan4466@gmail.com (W.N.); \\ A.Medina-Lara@exeter.ac.uk (A.M.-L.) \\ 2 College of Engineering, Mathematics and Physical Sciences, University of Exeter, Exeter EX4 4QF, UK; \\ H.T.P.Williams@exeter.ac.uk \\ 3 Alan Turing Institute, 96 Euston Rd, London NW1 2DB, UK \\ * Correspondence: rich.smith@exeter.ac.uk
}

Citation: Nie, Wan, Antonieta Medina-Lara, Hywel Williams, and Richard Smith. 2021. Do Health, Environmental and Ethical Concerns Affect Purchasing Behavior? A Meta-Analysis and Narrative Review. Social Sciences 10: 413. https:// doi.org/10.3390/socsci10110413

Academic Editor: Monica Magadi

Received: 7 September 2021

Accepted: 14 October 2021

Published: 26 October 2021

Publisher's Note: MDPI stays neutra with regard to jurisdictional claims in published maps and institutional affiliations.

Copyright: (c) 2021 by the authors. Licensee MDPI, Basel, Switzerland. This article is an open access article distributed under the terms and conditions of the Creative Commons Attribution (CC BY) license (https:// creativecommons.org/licenses/by/ $4.0 /)$.
Abstract: Much attention has been given to how we can make consumption more responsible-better for the planet and society. However, research on the associations between consumer purchasing behavior and their psychological concern for health, the environment and ethics lacks consensus on the significance and directionality of these concerns. This study aims to examine how (relatively) important these concerns are in determining consumer purchasing behavior. Systematic searches were conducted in PubMed, EconLit, Web of Science and Scopus databases from 2000 to 2020. Results were summarized through narrative synthesis of the evidence and meta-analysis. The meta-analysis revealed a significant positive correlation between health, environmental and ethical concerns and purchasing behavior, indicating that changes in health, environmental and ethical concerns will result in a consistent shift in purchase behavior towards choices consistent with the concern. This association is susceptible to moderating factors including types of products (food, non-food and non-specific products) and country's level of economic development. In addition, the health, environmental and ethical concerns appear to have a weaker impact on the actual purchase behavior than on purchase intention, suggesting that interventions should focus on translating these "purchasing intentions" into actual purchasing behaviors. Narrative review of the studies that were not subject to meta-analysis showed good agreement, with almost all relationships reported having the same direction as those indicated by the meta-analysis. Overall, this study suggests that there is substantial potential for marketing strategies aimed at encouraging pro-health, pro-environment and ethical purchasing behaviors.

Keywords: health; environment; ethical concern; purchase behavior; meta-analysis

\section{Introduction}

We have become increasingly aware of the impact of our daily consumption on the environment, our health and the lives of others. Much attention has therefore been given to how we can become more responsible consumers and make more consumption choices that are good for the planet and society. Consumer behavior is a highly complex process, influenced not only by prices and income, but also by a variety of preferences, which can be broadly categorized as egoistic (e.g., concern about one's health) and altruistic (e.g., concern about the physical environment and the ethical manner by which goods are produced (Birch et al. 2018; Ritter et al. 2015; Magnusson et al. 2003). However, there is no consensus on the directionality (positive, negative, or no effect) of these concerns on consumers' purchasing behavior (Konuk 2019; Nguyen et al. 2020; Birch et al. 2018; Liao et al. 2020). A positive association would imply that an increase in health, environmental and ethical concerns will result in a shift of purchasing towards choices indicated by these concerns; for example, buying more healthy products or fewer unhealthy products. A negative association would imply that an increase in these concerns will move purchasing away 
from choices indicated by these concerns; for example, buying more unethical products or fewer ethical products. No effect indicates that a shift in health, environmental and ethical concerns will not influence purchasing.

Some studies have reported that health, environmental and ethical concerns have a significant positive impact on purchasing behavior (Wang et al. 2020; Yazar and Burucuoglu 2019; Magnusson et al. 2003), whereas others find no association (Michaelidou and Hassan 2008; Jin et al. 2020). One study found a significant negative impact of ethical concern on consumers' purchasing intention towards genetically modified food (Kimenju and Groote 2008). The association between health, environmental and ethical concerns and a consumer's purchase behavior also appears to differ across different types of purchase behavior, product category and country's level of development (Yogananda Auroomooga and Nair 2019; Xu et al. 2020; Schill et al. 2019).

Consumer purchase behavior is an aggregation of a consumer's attitudes, preferences, intentions and decisions in the marketplace (Armstrong and Kotler 2016; Li et al. 2019). Based on the theory of planned behavior (TPB), purchase behavior can be divided into three categories: purchase intention, purchase attitude and purchase decision (Ajzen 1991). Purchase intention refers to the subjective probability or possibility of a consumer purchasing a particular product but not the actual purchase (Wu Jinnan et al. 2020). Purchase attitude is a psychological tendency to purchase a product that is expressed by evaluating a particular entity with some degree of favor or disfavor but is not the actual purchase (Lin and Huang 2012). Purchase decision refers to the actual purchase of the product (Nawi et al. 2019). In addition, purchase frequency defines how often the consumer purchases a product (Farías 2019). The willingness to pay a premium price for a product has also been widely applied to studies of consumer purchasing behavior. As a result, we include it as a separate type of consumer purchase behavior parallel to the remaining purchase behaviors (Zhang Biao et al. 2018).

Studies have investigated the effect of health, environmental and ethical concerns on consumer's purchase intention (Yogananda Auroomooga and Nair 2019), purchase attitude (Jin et al. 2020), purchase decision (Tan et al. 2019), purchase frequency (Kuhar and Juvancic 2010) and willingness to pay a premium price (Xu et al. 2020). These studies have had mixed results. For example, Kuhar and Juvancic (2010) found a positive association between health concern and customers' purchase intentions (Chu 2018), while Birch et al. (2018) found there was no such association between health concern and customers' purchase frequency.

There is also mixed evidence concerning the impact of product category-the type of product a customer is choosing to buy when making a purchasing decision. Depending on the product category, consumers perceive different levels of health, environmental and ethical concerns when making their purchasing decision. For example, a number of studies have assessed the association between health, environmental and ethical concerns and purchase behavior for food products (Wang et al. 2020) and non-food products (Xu et al. 2020) as well as non-specific product "categories" including green products such as eco-friendly items (Jin et al. 2020).

There is also a difference in purchasing behavior seen across levels of a country's economic development, as people have different economic abilities to buy a product (Li et al. 2020). There have been studies examining the correlation between health, environmental and ethical concerns and purchase behavior in both high-income (Uzdavinyte et al. 2019; Schill et al. 2019) and low- and middle-income countries (Tong and Kang 2019; Malik et al. 2019), with mixed findings. Studies suggest a positive association between health concern and purchase behavior in some developing countries, such as Turkey (Yazar and Burucuoglu 2019), but no such association in others, such as Thailand (Sriwaranun et al. 2015). Finally, of course, methodologies used in investigating the correlation between health, environmental and ethical concerns and purchase behavior also vary (Fynn-Green et al. 2019; Prakash et al. 2018). 
Overall, the clear lack of consensus with respect to the relationship between health, environmental and ethical concerns and purchase behavior (Yogananda Auroomooga and Nair 2019; Svecova and Odehnalova 2019; Shukla 2019) makes it difficult to design and assess marketing strategies to encourage pro-health, pro-environment or ethical purchasing behaviors. This study aims to fill the research gap by bringing together empirical evidence for the association between health, environmental and ethical concerns and consumer purchase behavior through meta-analysis and narrative review. The findings provide a robust estimate of the significance and directionality of relationships between consumer concerns and purchasing behaviors and a positive message for developing interventions intended to promote more responsible consumption.

\section{Methods}

This meta-analysis was conducted in accordance with the PRISMA flow guidelines for such reviews. The recommended protocol was followed.

\subsection{Search Strategy and Study Selection}

We conducted searches of both peer-reviewed scientific journals and "grey" literature identified from online databases. The search used keywords such as: "health concern", "health conscious", "environmental concern", "environmental conscious", "ethical conscious", "ethical concern", "purchase", "shop", "buy", "factor", "impact", "effect", "determine", "drive" (Supplement S1). The PubMed, EconLit, Web of Sciences and Scopus databases were searched from January 2000 to March 2020, a two-decade period during which social attention towards health, environmental and ethical concerns has been growing and may be reflected in consumer purchase behavior (Ghvanidze et al. 2016; Ritter et al. 2015; Seyfang 2005).

\subsection{Inclusion and Exclusion Criteria}

The inclusion criteria were:

1. Articles published in English language;

2. Articles contain empirical data (including panel and cross-sectional data);

3. Studies should focus on at least one of the three concerns (health, environmental and ethical);

4. Studies should focus on consumer purchasing, including purchase intention, purchase attitude, purchase decision, purchase frequency and/or willingness to pay a premium price;

5. Purchasing was by consumers for themselves and/or for their households, not, e.g., corporate purchases by companies/organizations;

6. The subjects were adult consumers;

7. The geographic area/countries were not restricted.

Articles were excluded based on the following criteria:

1. Proceedings papers, qualitative studies, systematic reviews, experimental studies, and conceptual studies;

2. Studies focusing on product consumption, purchasing places (e.g., online shopping) or other decisions or behavior (e.g., conservation, openness to change, self-enhancement, and self-transcendence) that are not purchasing behavior;

3. Studies with moderating or indirect role of health, environmental and ethical concerns on purchasing behavior.

\subsection{Data Extraction and Synthesis}

Two reviewers independently screened titles and abstracts to identify studies that could be included and any conflicting opinions were adjudicated by a third reviewer. After title and abstract review, each article that met the inclusion criteria was reviewed in full and data were extracted with respect to: author(s), year of publication, concern (health, environmental and ethical), purchase attitude, purchase intention, purchase deci- 
sion, purchase frequency and willingness to pay a premium price, methods to measure purchasing behavior, purchase product, methods to collect data, country or region, sample size, correlation coefficient, statistical methods to analysis data and the results.

\subsection{Effect Size Computation}

We selected Pearson's correlation coefficient $r$ for representing effect size (Card 2015). In some publications, extracting the necessary information for calculating a Pearson's $\mathrm{r}$ was not possible (Supplements S2 and S3) and could not be included in our primary meta-analysis (Card 2015; Polman and Wu 2019). A positive $r$ indicates a positive shift towards the decision indicated by the concern. The confidence intervals and hypothesis tests relating to $r$ are usually carried out using the Fisher transformation, denoted as $Z_{r}$ :

$$
\begin{gathered}
Z_{r}=\frac{1}{2} \ln \frac{1-r}{1+r} \\
r \in[-1,+1]
\end{gathered}
$$

Here, $Z_{r}$ is the effect size and approximately follows a normal distribution with the standard error:

$S E_{Z_{r}}=\frac{1}{\sqrt{n-3}}$ where $n$ is the sample size.

\subsection{Risk of Bias Assessment}

Risk of bias assessment was used to evaluate the quality of the 54 studies included in the meta-analysis. Six items adapted from previously developed risk of bias instruments (Li et al. 2020; Viswanathan et al. 2013) were employed in this study. For each item, the response options are no, yes and unclear (Table 1).

\begin{tabular}{|c|c|c|c|c|}
\hline \multirow{2}{*}{$\begin{array}{l}\text { Risk of Bias } \\
\text { Criteria }\end{array}$} & \multirow{2}{*}{ Description } & \multicolumn{3}{|c|}{ Risk- $n$ (\%) } \\
\hline & & High & Low & Unclear \\
\hline Selection bias & $\begin{array}{l}\text { Is there a random sampling in the } \\
\text { study? }\end{array}$ & $11(20.37)$ & $30(55.56)$ & $13(24.07)$ \\
\hline $\begin{array}{l}\text { Performance } \\
\text { bias }\end{array}$ & $\begin{array}{l}\text { Do investigators and respondents } \\
\text { know the purpose of the study? } \\
\text { Does the study report the }\end{array}$ & $0(0)$ & 18 (33.33) & $36(66.67)$ \\
\hline Detection bias & $\begin{array}{l}\text { reliability and validity of the } \\
\text { measurement tool used in the } \\
\text { study? }\end{array}$ & $4(7.41)$ & $50(92.59)$ & $0(0)$ \\
\hline Attribution bias & $\begin{array}{c}\text { Are there explanations for the } \\
\text { proportion of valid } \\
\text { questionnaires? }\end{array}$ & $0(0)$ & $32(59.26)$ & $22(40.74)$ \\
\hline Reporting bias & $\begin{array}{l}\text { Is the basic information } \\
\text { description of the sample } \\
\text { complete? Are the results of the } \\
\text { study reported truthfully (e.g., } \\
\text { both positive and negative results } \\
\text { are reported?) }\end{array}$ & $18(33.33)$ & $36(66.67)$ & $0(0)$ \\
\hline Other bias & $\begin{array}{l}\text { Is there theoretical basis? Is there } \\
\text { hypothesis development? }\end{array}$ & $4(7.41)$ & $50(92.59)$ & $0(0)$ \\
\hline
\end{tabular}

Table 1. Risk of bias assessment of 54 eligible articles included in the meta-analysis.

\section{Meta-Analysis}

A random-effects model was adopted to create forest maps and funnel plots and to conduct heterogeneity analysis, meta-analysis, subgroup analyses and article weight analysis. The random effects model was selected due to its consistency with reality (Sriram 2018). First, the random effects model of Hedges was used to explain the heterogeneity between studies (Basu 2017). Second, heterogeneity was tested using the I-squared statistic 
$\left(I^{2}\right)$ and tested with a chi-squared test. A high I-squared statistic would mean gross heterogeneity, while a low I-squared value would imply homogeneity of the studies (usually conventionally set as 30\%) (Basu 2017). Third, each study was weighted, and the effect size and confidence intervals were displayed in forest maps, along with the overall effect size. Fourth, subgroup analyses were conducted to examine the associations between the three concerns of interest and the types of purchase behavior (Murray et al. 2017). Fifth, moderator analyses were performed to investigate the influence of types of products and country development level on the associations between health, environmental and ethical concerns and customer purchase behavior ( $\mathrm{Li}$ et al. 2020; Lin and Huang 2012); Table 2 presents a summary of each moderator's classification. Sixth, publication bias was assessed through funnel plots. Finally, we assessed robustness by performing the fail-safe $\mathrm{N}$ test, which refers to the number of studies needed to reverse the results of the meta-analysis. It is considered difficult to change the meta-analysis results when the required studies exceed $5 K+10$ ( $K$ is the number of studies included) (Basu 2017). The fail-safe $N$ test was conducted with Comprehensive Meta-Analysis version 3.0 (CMA 3.0). Significance was defined as $p<0.01$ (two-sided). The remaining meta-analyses were conducted in Stata 16.0. 
Table 2. Characteristics of the 54 studies included in the meta-analysis.

\begin{tabular}{|c|c|c|c|c|c|c|}
\hline Author (Year) & Country & Sample Size & Concern & Purchase Decision & $\begin{array}{l}\text { Measure Purchase } \\
\text { Decision }\end{array}$ & Product Category \\
\hline Wang et al. (2020) & China & 518 & EnvC & Purchase intention & 7-point Likert scale & Organic food \\
\hline Xu et al. (2020) & China & 460 & $\begin{array}{l}\mathrm{HC} \\
\text { EnvC }\end{array}$ & Purchase attitude & 5-point Likert scale & Green furniture \\
\hline Xu et al. (2020) & China & 460 & EnvC & $\begin{array}{l}\text { Willingness to pay a } \\
\text { premium price }\end{array}$ & 5-point Likert scale & Green furniture \\
\hline Xu et al. (2020) & China & 460 & $\mathrm{HC}$ & Purchase intention & 5-point Likert scale & Green furniture \\
\hline Jin et al. (2020) & China & 336 & $\begin{array}{l}\mathrm{HC} \\
\text { EnvC }\end{array}$ & Purchase attitude & 7-point Likert scale & Eco-labelled products \\
\hline Jin et al. (2020) & China & 336 & $\begin{array}{l}\mathrm{HC} \\
\text { EnvC }\end{array}$ & Purchase intention & 7-point Likert scale & Eco-labelled products \\
\hline Konuk (2019) & Turkey & 478 & $\begin{array}{c}\text { EnvC } \\
\text { EC }\end{array}$ & Purchase intention & 5-point scale & Fair trade food \\
\hline Yazar and Burucuoglu (2019) & Turkey & 388 & $\mathrm{HC}$ & Purchase attitude & 5-point scale & Organic food \\
\hline Yazar and Burucuoglu (2019) & Turkey & 388 & $\mathrm{HC}$ & Purchase intention & 5-point scale & Organic food \\
\hline Testa et al. (2019) & Italy & 79 & $\mathrm{HC}$ & Purchase attitude & 7-point scale & Organic food \\
\hline Wang et al. (2019) & Tanzania & 331 & $\mathrm{HC}$ & Purchase intention & 5-point scale & Organic food \\
\hline Wang et al. (2019) & Kenya & 350 & $\mathrm{HC}$ & Purchase intention & 5-point scale & Organic food \\
\hline Shukla (2019) & India & 423 & EnvC & Purchase intention & 6-point scale & Green products \\
\hline Schill et al. (2019) & France & 641 & EnvC & Purchase intention & 5-point Likert scale & Eco-friendly smart home objects \\
\hline Salimi (2019) & Iran & 359 & EnvC & Purchase attitude & 5-point Likert scale & Green products \\
\hline Salimi (2019) & Iran & 359 & EnvC & Purchase intention & 5-point Likert scale & Green products \\
\hline Saleki et al. (2019) & Malaysia & 246 & EnvC & Purchase intention & 5-point Likert scale & Organic food \\
\hline Nguyen et al. (2019) & Vietnam & 295 & $\begin{array}{l}\mathrm{HC} \\
\text { EnvC }\end{array}$ & Purchase attitude & 5-point Likert scale & Organic cosmetic \\
\hline Nguyen et al. (2019) & Vietnam & 596 & $\mathrm{HC}$ & Purchase attitude & 7-point Likert scale & Functional yogurt \\
\hline Malik et al. (2019) & Pakistan & 1008 & EnvC & Purchase decision & 5 -point scale & Green products \\
\hline Li et al. (2019) & China & 305 & EnvC & Purchase attitude & 5-point scale & Energy-Efficient appliances \\
\hline Li et al. (2019) & China & 305 & EnvC & Purchase intention & 5-point scale & Energy-Efficient appliances \\
\hline Heo and Muralidharan (2019) & United States & 283 & EnvC & Purchase decision & 5-point scale & Eco-friendly products \\
\hline Augustine et al. (2019) & Malaysia & 374 & EnvC & Purchase decision & 5-point scale & Sustainable Fashion \\
\hline Chu (2018) & China & 1421 & $\begin{array}{l}\mathrm{HC} \\
\text { EnvC }\end{array}$ & Purchase attitude & 5-point Likert scale & Organic food \\
\hline Chu (2018) & China & 1421 & $\mathrm{HC}$ & Purchase intention & 5-point Likert scale & Organic food \\
\hline
\end{tabular}


Table 2. Cont.

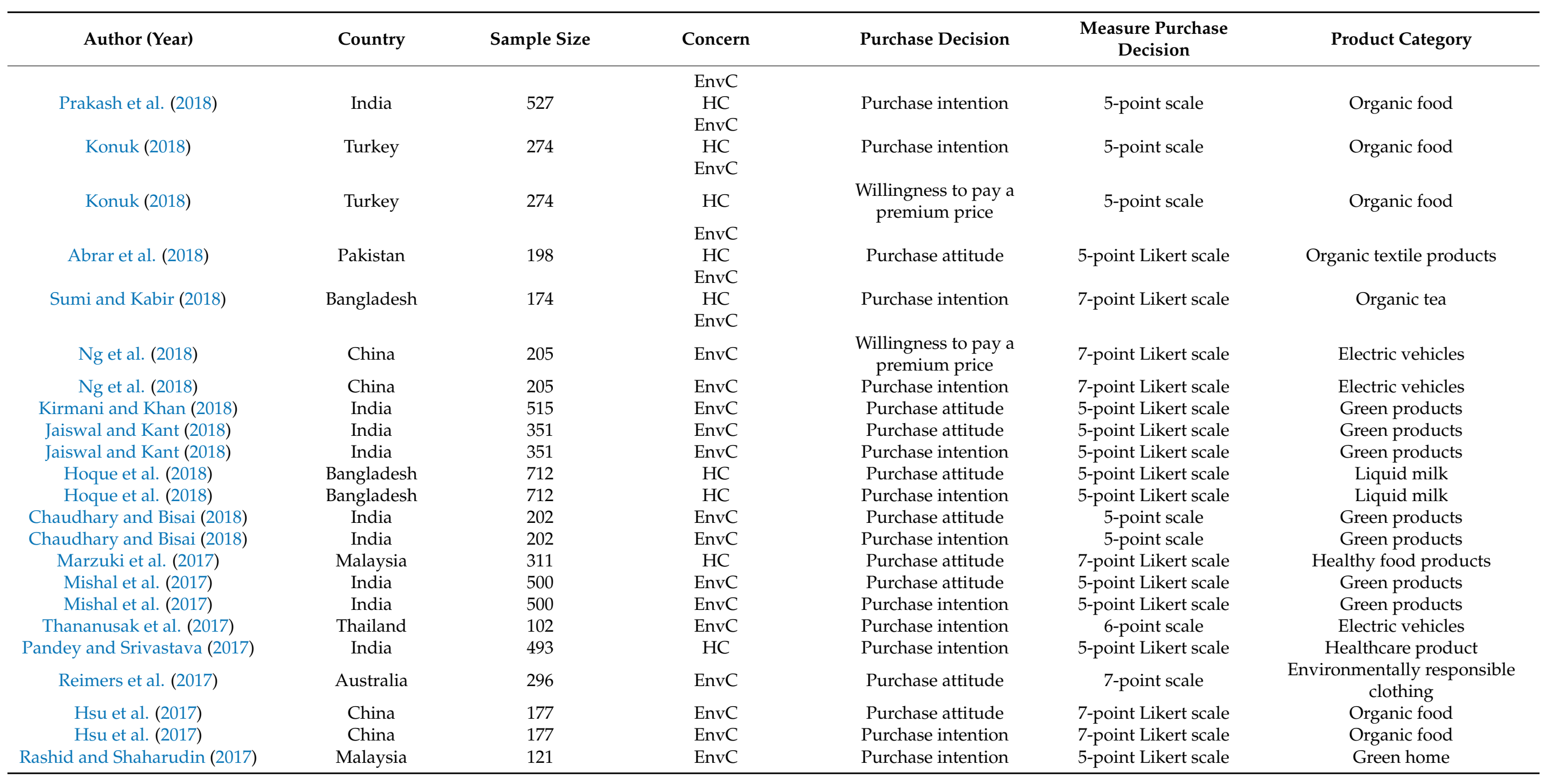


Table 2. Cont.

\begin{tabular}{|c|c|c|c|c|c|c|}
\hline Author (Year) & Country & Sample Size & Concern & Purchase Decision & $\begin{array}{c}\text { Measure Purchase } \\
\text { Decision }\end{array}$ & Product Category \\
\hline Yadav and Pathak (2016a) & India & 220 & $\begin{array}{l}\mathrm{HC} \\
\text { EnvC }\end{array}$ & Purchase attitude & 5-point Likert scale & Organic food \\
\hline Wang et al. (2016) & China & 433 & EnvC & Purchase attitude & 5-point Likert scale & Hybrid electric vehicles \\
\hline Yadav and Pathak (2016b) & India & 326 & EnvC & Purchase attitude & 5-point Likert scale & Green products \\
\hline Yadav and Pathak (2016b) & India & 326 & EnvC & Purchase intention & 5-point Likert scale & Green products \\
\hline Hwang (2016) & United States & 222 & EnvC & Purchase intention & 5-point scale & Organic food \\
\hline Hsu et al. (2016) & China & 252 & $\mathrm{HC}$ & Purchase attitude & 7-point scale & Organic food \\
\hline Hsu et al. (2016) & China & 252 & $\mathrm{HC}$ & Purchase intention & 7-point scale & Organic food \\
\hline Lee (2016) & Korea & 898 & $\begin{array}{l}\mathrm{HC} \\
\text { EnvC }\end{array}$ & Purchase attitude & 7-point scale & Organic food \\
\hline Basha et al. (2015) & India & 50 & $\begin{array}{l}\mathrm{HC} \\
\text { EnvC }\end{array}$ & Purchase intention & 5-point Likert scale & Organic food \\
\hline Çabuk et al. (2014) & Turkey & 385 & $\begin{array}{l}\mathrm{HC} \\
\text { EnvC }\end{array}$ & Purchase attitude & 5-point Likert scale & Organic food \\
\hline Yoo et al. (2013) & United States & 122 & EnvC & Purchase intention & 5-point scale & Bamboo products \\
\hline Suki (2013) & Malaysia & 200 & EnvC & Purchase decision & 5-point Likert scale & Green products \\
\hline Pino et al. (2012) & Italy & 291 & $\mathrm{HC}$ & Purchase attitude & 7-point Likert scale & Organic food \\
\hline Pino et al. (2012) & Italy & 291 & $\mathrm{HC}$ & Purchase intention & 7-point Likert scale & Organic food \\
\hline Voon et al. (2011) & Malaysia & 300 & EnvC & Purchase decision & 5-point Likert scale & Green products \\
\hline Lee (2011) & United States & 150 & EnvC & $\begin{array}{l}\text { Willingness to pay a } \\
\text { premium price }\end{array}$ & 7-point scale & Green apparel products \\
\hline Michaelidou and Hassan (2010) & United Kingdom & 222 & $\mathrm{HC}$ & Purchase attitude & 7-point scale & Organic and fair trade \\
\hline Michaelidou and Hassan (2010) & United Kingdom & 222 & $\mathrm{HC}$ & Purchase intention & 7-point scale & Organic and fair trade \\
\hline Smith and Paladino (2010) & Australia & 157 & $\begin{array}{c}\mathrm{HC} \\
\text { EnvC }\end{array}$ & Purchase attitude & 5 -point Likert scale & Organic food \\
\hline Chen (2009) & China & 470 & $\mathrm{HC}$ & Purchase attitude & 7-point Likert scale & Organic food \\
\hline Kim and Seock (2009) & United States & 210 & $\begin{array}{l}\mathrm{HC} \\
\text { EnvC }\end{array}$ & Purchase frequency & 5-point Likert scale & Natural beauty products \\
\hline Michaelidou and Hassan (2008) & United Kingdom & 222 & $\mathrm{HC}$ & Purchase attitude & 7-point scale & Organic food \\
\hline Michaelidou and Hassan (2008) & United Kingdom & 222 & $\mathrm{HC}$ & Purchase intention & 7-point scale & Organic food \\
\hline
\end{tabular}




\section{Results}

\subsection{Review of the Studies Included in the Meta-Analysis}

In total, 29,250 papers were initially identified based on the search strategy from four databases (see Supplement S1 for details) and three studies were retrieved from Google Scholar. After removal of duplicates, there were 18,156 articles left. Of these, 18,102 articles were excluded based on the inclusion and exclusion criteria and the remaining 104 articles were fully assessed. Of these, 50 articles did not report a correlation coefficient $\mathrm{r}$ or were not able to calculate $r$ (Supplements S2 and S3), resulting in 54 articles that were finally included in the meta-analysis. Below is a flow diagram showing a summary of the search and selection process employed for identifying papers included in the meta-analysis (see Figure 1).



Figure 1. The search and selection process for identifying papers included in the meta-analysis.

\subsubsection{Publication Timeline and Geographical Scope}

Of the 54 articles included in the meta-analysis, the annual number of articles published showed an increasing trend between 2015 and 2019 (Figure 2a), and a few studies were published in the remaining years (2008-2014). However, the effect sizes of the association between health and environmental concerns and purchasing behavior fluctuated between 2008 and 2020, indicating the effect sizes of the included studies did not appear to be related to time. The selected studies focused on a broader geographical scope including United States, United Kingdom, Europe and Asia and countries with different levels of economic development ranging from high-income economies including the USA, UK, France, Italy, Lithuania, Australia, to low- and middle-income economies including China, India, Iran, Kenya, South Korea, Malaysia, Pakistan, Bangladesh, Thailand, Turkey, Vietnam, Tanzania and Cambodia. ${ }^{1}$ 


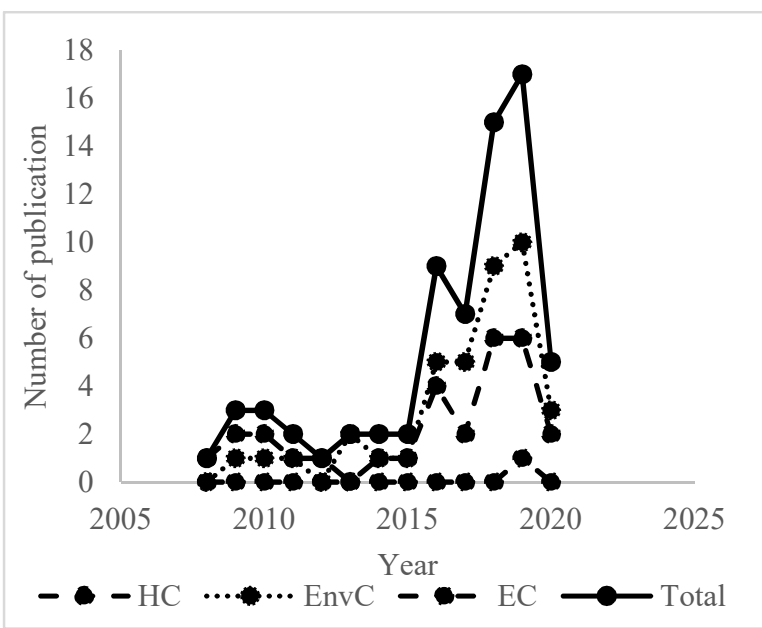

(a)

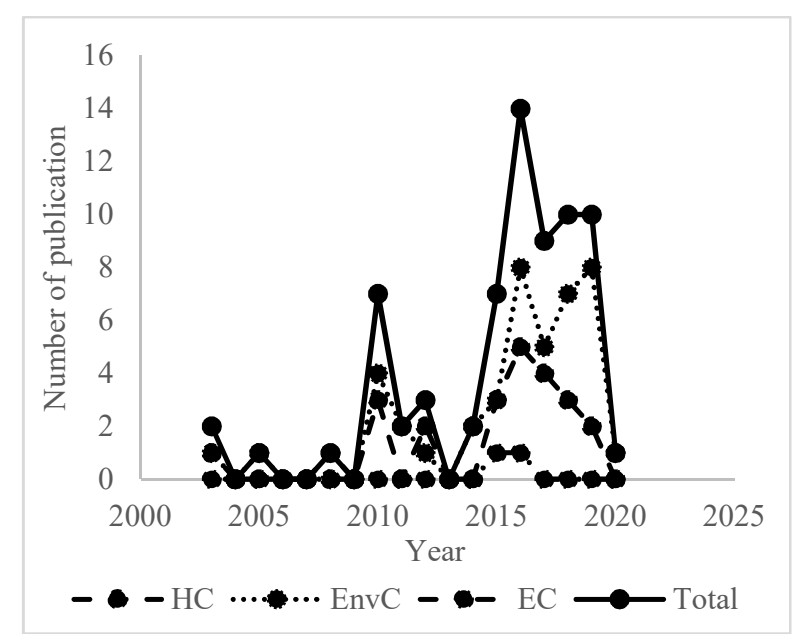

(b)

Figure 2. Distribution of 54 publications included in the meta-analysis (a) and 50 articles not included in the metaanalysis (b).

\subsubsection{Purchase Product Category}

Of the 54 studies included in the meta-analysis, 24 focused on food products, 18 focused on non-food products and the remaining 12 papers focused on non-specific products (where the paper did not state what the product was, such as various products described as "green" or "environmentally friendly"; these may be food and/or non-food products). Among the food purchasing behavior, the most investigated food product was organic food. The other, less discussed, food products were fair trade food, domestic food, functional food and healthy food. The most examined non-food products were electric vehicles, energy-efficient appliances, organic clothing, and organic cosmetics. Non-specific products included eco-friendly products, eco-labelled products and other green products, detailed in Table 2.

\subsubsection{Dependent Variables Applied to Represent Purchase Behavior}

Of the 54 studies, 36 selected purchase intention as representing the purchase behavior, 29 used purchase attitude, 5 purchase decision, 1 adopted purchase frequency and 4 studies adopted consumers' willingness to pay a premium price for products. In line with the dependent variables, 23 studies adopted a five-point Likert scale and the remaining 31 studies used Likert-type scales to measure consumer purchase behavior. Sample sizes ranged from 50 to 9470 (Table 2).

\subsubsection{Methods Used to Collect and Analyze Data}

Of the 54 studies, 43 used structural equation modelling (SEM) to analyze the data. There were 10 studies that adopted regression methods to examine the relationship between health, environmental and ethical concerns and purchasing behavior. The remaining study applied a correlation analysis method to analyze the data (Table 2).

\subsubsection{Results of Risk of Bias Assessment}

The risk of bias assessment scores of the included studies in meta-analysis are shown in Table 1. The assessment had six specific aspects: selection, performance, detection, attribution, reporting and other bias. Overall, the included studies had low risk of publication bias, with approximately 4 papers with high scores $(7.4 \%)$, and approximately 50 articles with low scores $(92.6 \%)$. 


\subsubsection{Robustness Test}

In terms of the association between health concern and consumer purchase behavior, the fail-safe $\mathrm{N}$ test shows that the number of missing studies that would bring $p$-value to $>$ alpha (alpha $=0.01)$ is 4216 , which is far more than $220(5 \mathrm{~K}+10$, where $\mathrm{K}=42)$. With respect to the number of studies needed to reverse the results of the meta-analysis regarding the association between environmental concern and purchase behavior, 9428 articles are needed, which exceed $280(5 K+10$, where $K=54)$. The results mean that even if there was publication bias, it had little impact on the results and was tolerable and negligible.

4.2. Results Regarding the Effect of Health, Environmental and Ethical Concerns on Purchase Behavior

4.2.1. The Effect of Health Concern on Purchase Behavior

Of the 54 articles included in the meta-analysis, 29 addressed the effect of health concern on purchasing behavior and reported a correlation coefficient for the relationship between them. The correlation coefficient varied from 0.038 to 0.65 . The statistical heterogeneity across the studies was high $\left(I^{2}\right.$ percent, $\left.p<0.001, Q=747.12\right)$. The overall effect size between health concern and consumer purchase behavior was 0.38 , with a $95 \%$ confidence interval ranging from 0.32 to 0.44 . More specifically, all of the 29 studies reported a positive impact of health concern on consumer purchase behavior. The complete collection of information is summarized in Figure 3 and Table 2. The unsymmetrical funnel plot shown in Figure 4 led us to conduct robustness analysis (described in the above section). 


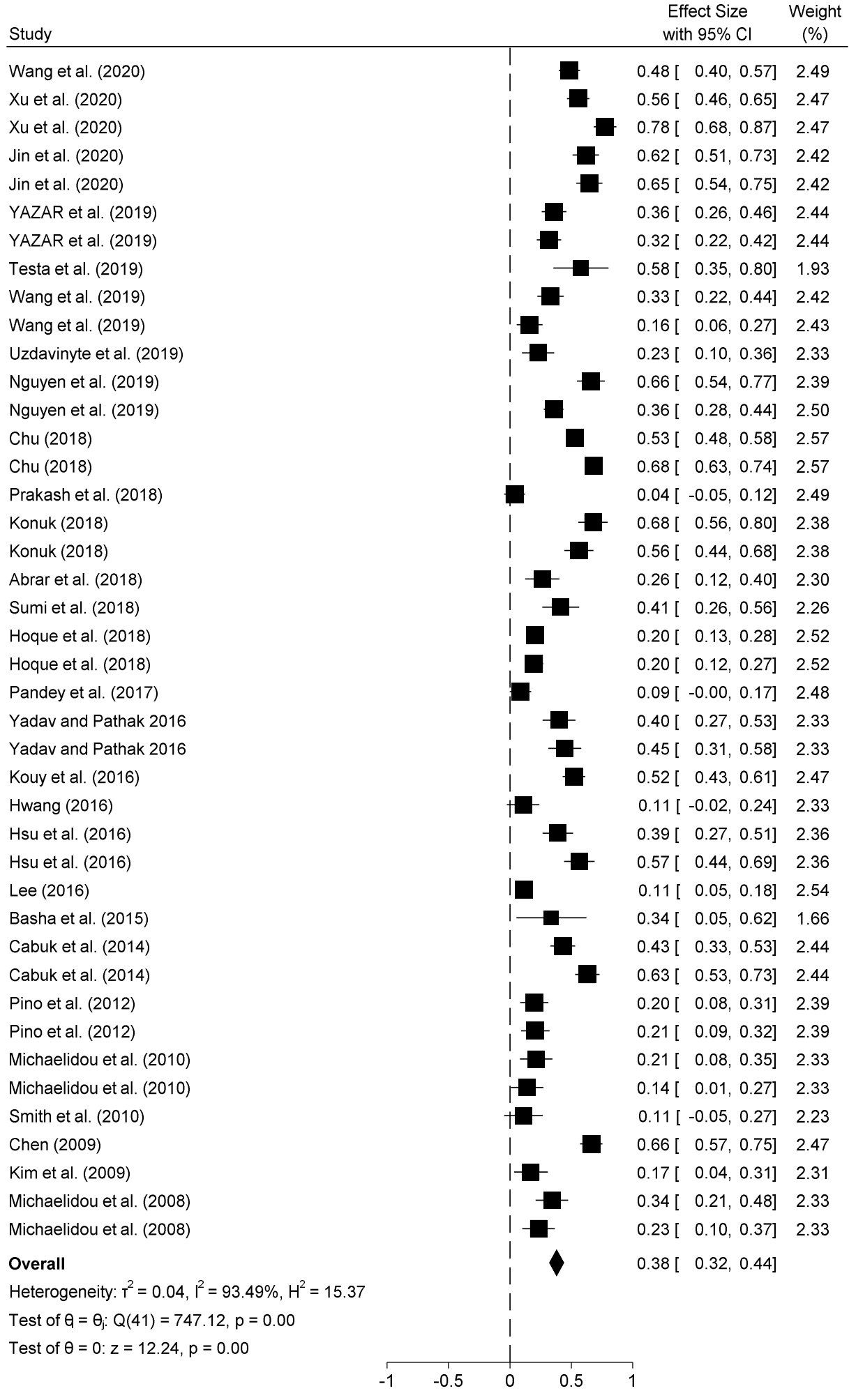

Random-effects Hedges model

Figure 3. Meta-analysis of the association between health concern and consumer purchase behavior. 


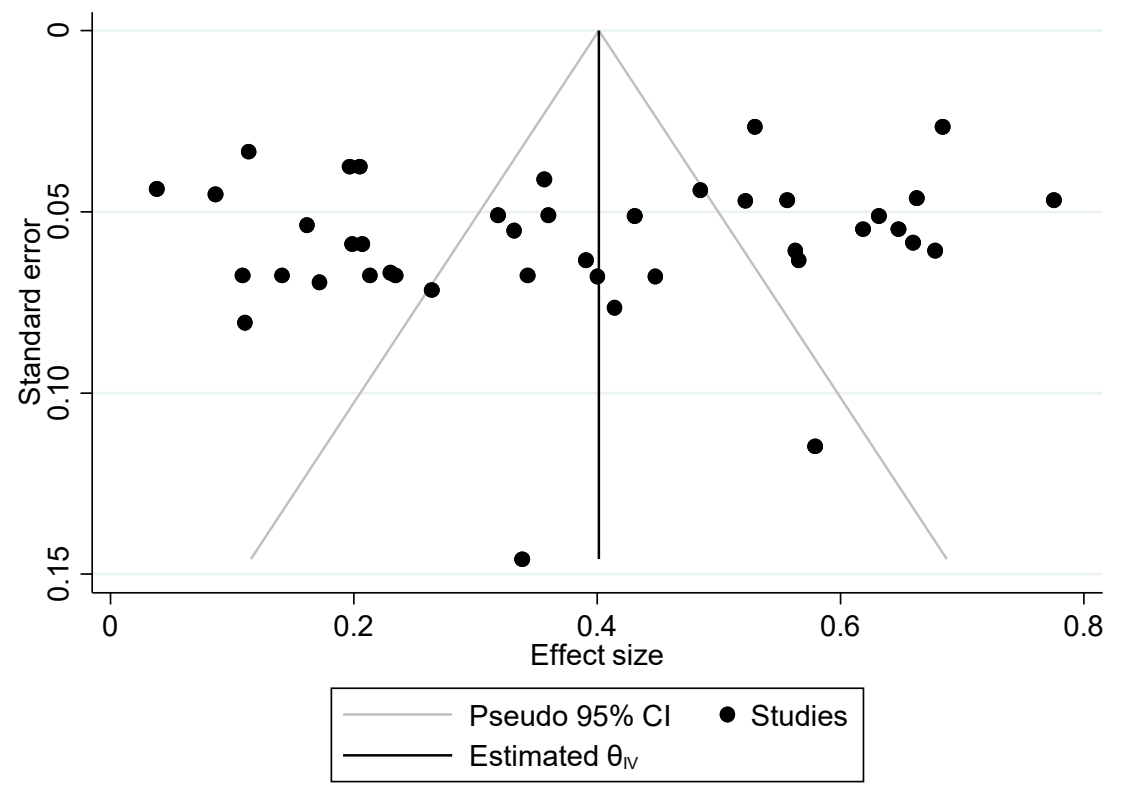

Figure 4. Funnel plot of the 29 articles investigated the association between health concern and consumer purchase behavior.

\subsubsection{The Effect of Environmental Concern on Purchase Behavior}

Of the 54 articles included, 39 addressed the association between environmental concern and customer purchase behavior and reported a correlation coefficient for the relationship between them $(72.2 \%)$. The correlation coefficient varied from 0.05 to 0.74 . The statistical heterogeneity across the studies was high $\left(I^{2}=93.13\right.$ percent, $p<0.001$, $Q=921.19$ ). The overall effect size between environmental concern and customer purchase behavior was 0.45 , with a 95 percent confidence interval ranging from 0.39 to 0.50 . More specifically, all of the 39 studies reported that the environmental concern had a positive impact on consumer purchase behavior. The complete collection of information is summarized in Figure 5 and Table 2. The unsymmetrical plot is shown in Figure 6 and the robustness test illustrates that publication bias in the findings (if there is any) is sufficiently small that it can be ruled out as a potential concern.

\subsubsection{The Effect of Ethical Concern on Purchase Behavior}

Of the 54 studies, only 1 addressed the effect of ethical concern on purchase behavior and reported a correlation coefficient for the relationship between them. The correlation coefficients were 0.43 and 0.65 . The statistical heterogeneity was high $\left(I^{2}=85.92\right.$ percent, $p<0.001, Q=7.10$ ). The overall effect size between ethical concern and customer purchase behavior was 0.55 , with a 95 percent confidence interval ranging from 0.38 to 0.72 . Overall, ethical concern had a positive impact on customer purchase behavior in the included study. The complete collection of information is summarized in Figure 7 and Table 2. The symmetrical plot shown in Figure 8 illustrates no publication bias in our data regarding the association between ethical concern and consumer purchase behavior. 


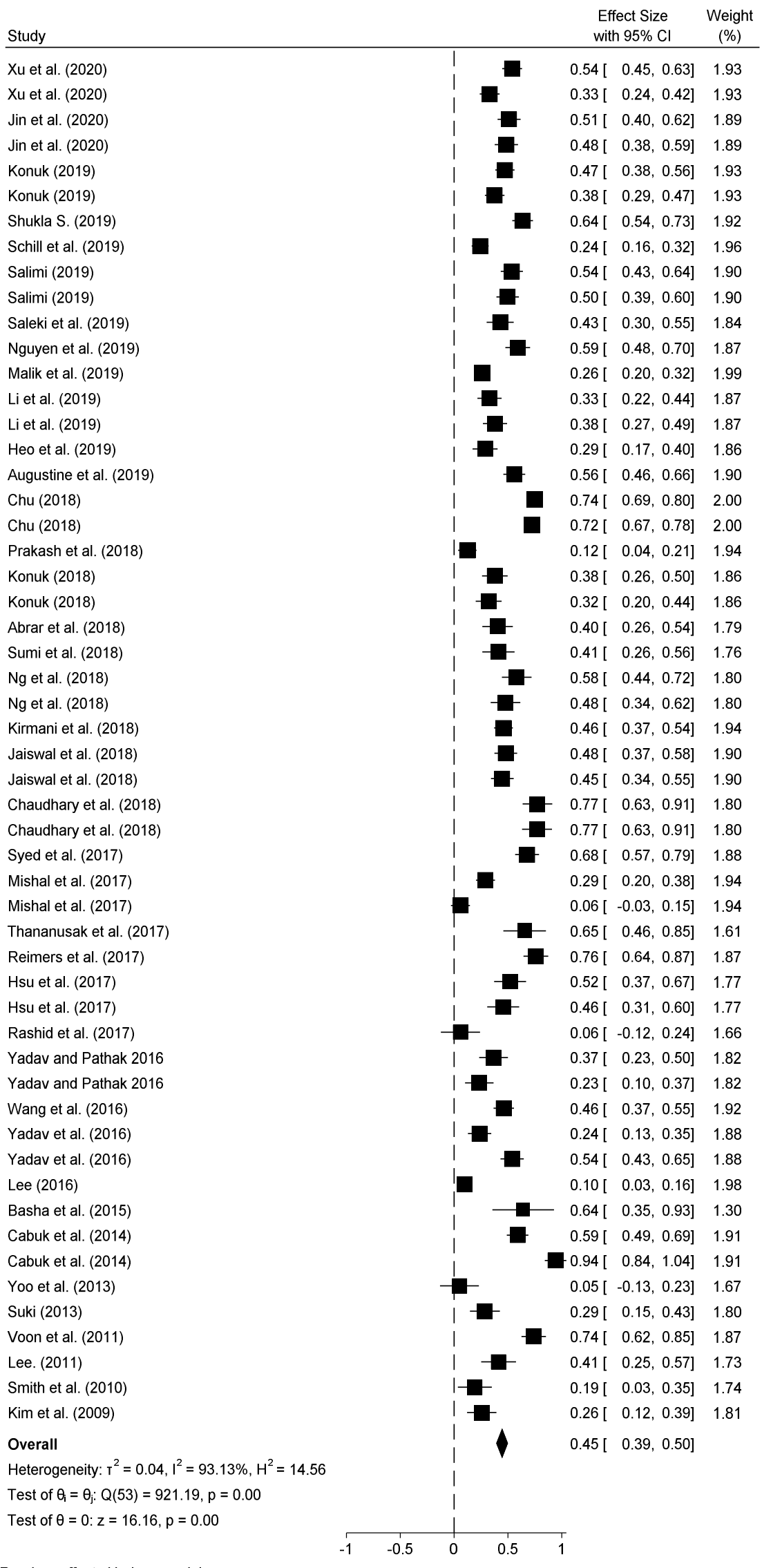

Figure 5. Meta-analysis of the association between environmental concern and consumer purchase behavior. 


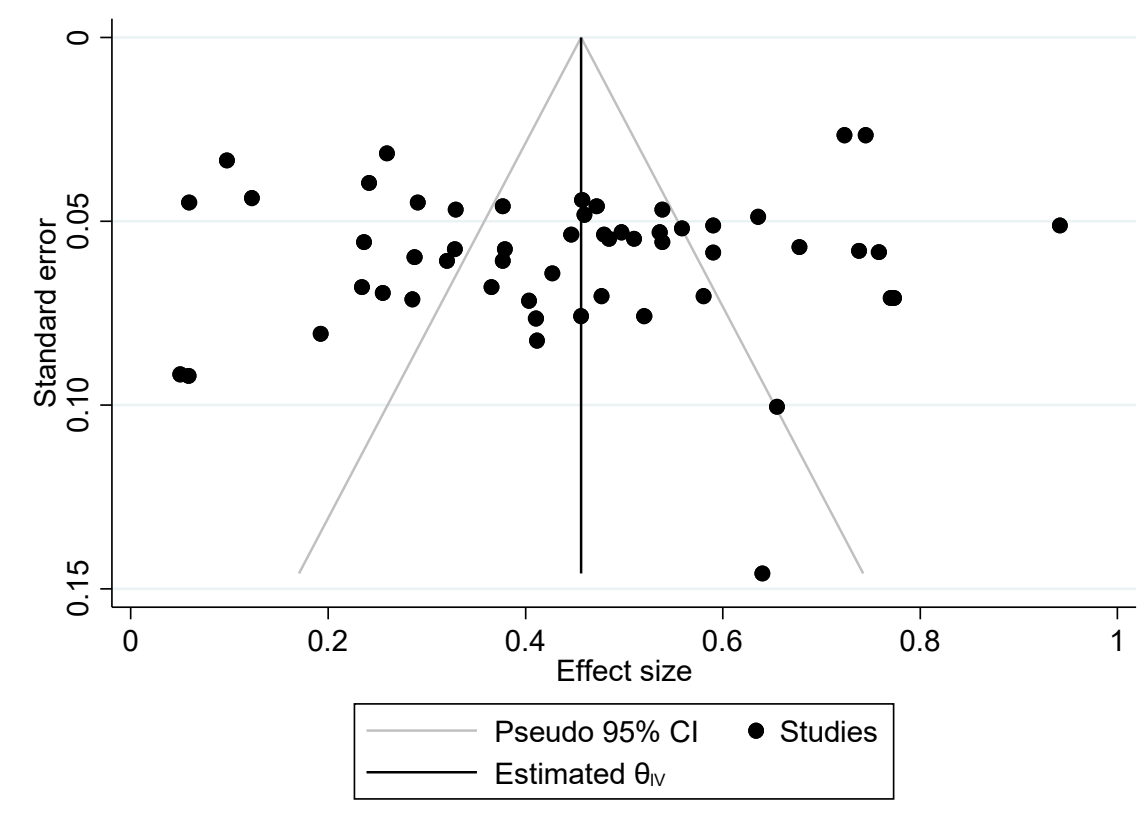

Figure 6. Funnel plot of the 39 articles that investigated the association between environmental concern and consumer purchase behavior.

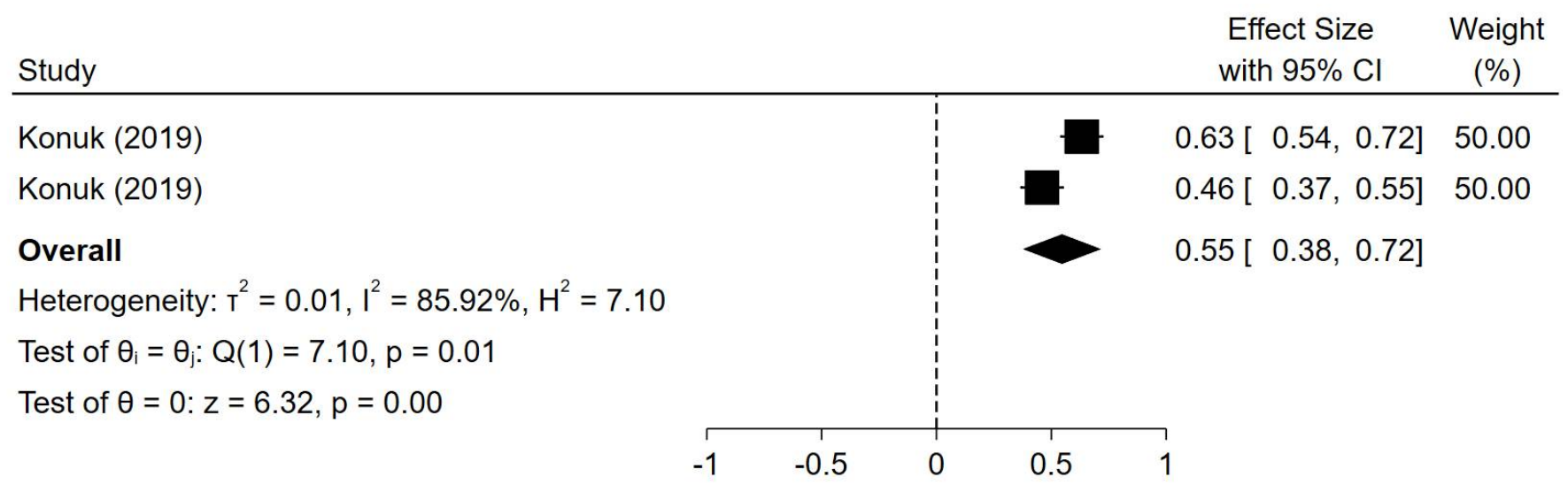

\section{Random-effects Hedges model}

Figure 7. Meta-analysis of the association between ethical concern and consumer purchase behavior.

4.2.4. Results of the Impact of Health, Environmental and Ethical Concerns on Different Types of Purchase Behavior

Of the 29 studies that investigated the relationship between health concern and purchase behavior, the overall effect size in purchase intention was 0.38 . The overall effect size was 0.39 for purchase attitude, 0.17 for purchase frequency, and 0.56 for willingness to pay a premium price. The results indicate that health concern has a positive influence on purchase intention, purchase attitude, purchase frequency and willingness to pay a premium price. 


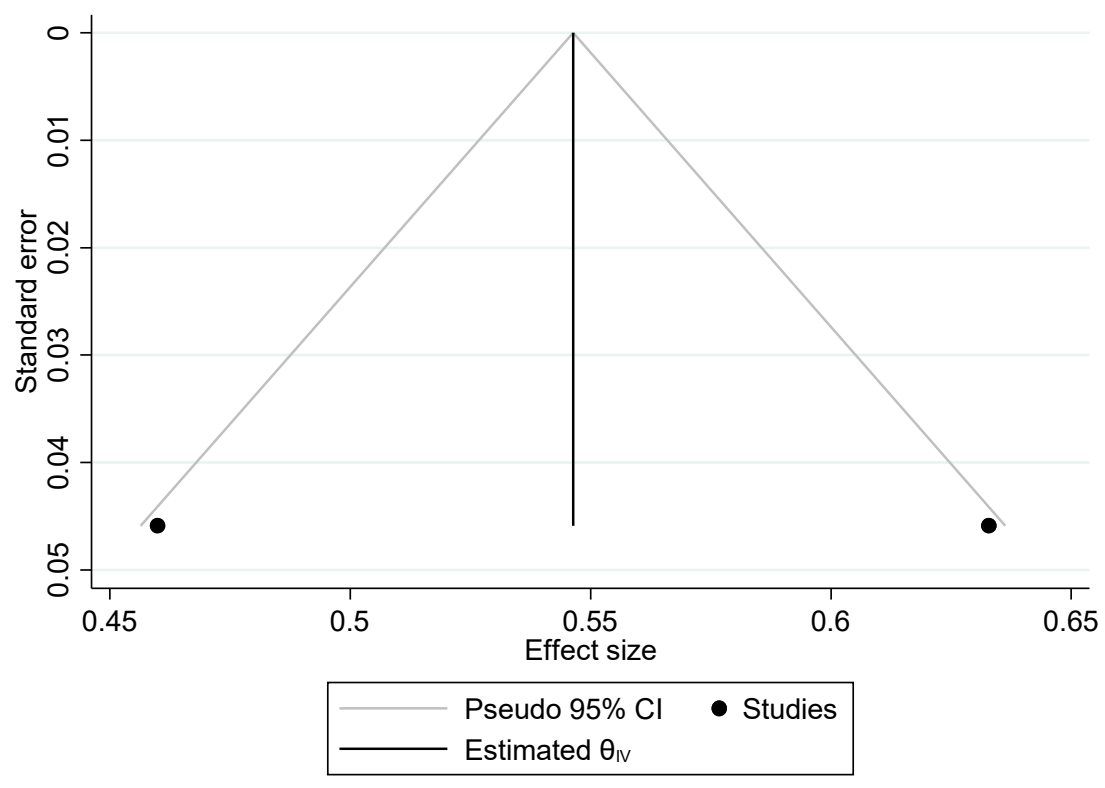

Figure 8. Funnel plot of the association between ethical concern and consumer purchase behavior.

Of the 39 studies that investigated the association between environmental concern and customer purchase behavior, the overall effect size in customer purchase intention, purchase attitude, purchase decision, purchase frequency and willingness to pay a premium price was $0.44,0.48,0.43,0.26$ and 0.4 , respectively, illustrating environmental concern has a positive impact on purchase intention, purchase attitude, purchase decision, purchase frequency and willingness to pay a premium price.

Only one study investigated the correlation between ethical concern and purchase behavior. It reported a correlation between ethical concern and purchase intention, and between ethical concern and willingness to pay a premium price, with effect sizes of 0.63 and 0.55 , respectively. The overall association between ethical concern and consumer purchase behavior is positive.

\subsection{Results for Moderators}

As there was considerable variance between studies $\left(Q=747.12, I^{2}=93.49\right.$ percent for health concern; $Q=921.19, I^{2}=93.13$ percent for environmental concern; $Q=7.10$, $I^{2}=85.92$ percent for ethical concern), subgroup analyses were conducted to explore heterogeneity by showing how effect sizes differed between groups of studies. Studylevel characteristics included types of purchase behavior, product category and country's economic development level. Subgroup analyses found significant differences for types of purchase behavior, product category and country's economic development level $(p<0.01)$, as presented in Table 3.

\subsubsection{Types of Products}

The effect size differed among types of products. In general, the effect size in nonfood products was stronger than that in food products with regard to the association between health concern and purchase behavior. However, the effect size in food products was stronger than that in non-food products with respect to the correlation between environmental concern and consumer purchase behavior.

Of the 29 studies examining the association between health concern and purchase behavior, the overall effect size in food, non-food and non-specific product was $0.38,0.42$ and 0.18 , respectively. Of the 39 studies investigating the relationship between environmental concern and purchase behavior, the overall effect size was highest in food (0.46) and lowest in non-food (0.43), and the non-specific product had an overall effect size of 
0.45. The single study investigating the relationship between ethical concern and purchase behavior focused on food, with an overall effect size of 0.55 .

Table 3. The overall effect sizes and heterogeneity analysis of the association between health, environmental and ethical concerns and purchase behavior by types of purchase behavior, product category and country's development level.

\begin{tabular}{|c|c|c|c|}
\hline \multirow{2}{*}{ Type } & \multicolumn{3}{|c|}{ Effect Size } \\
\hline & $\mathrm{HC}^{\mathrm{a}}$ & EnvC a & $\mathrm{EC}^{\mathrm{a}}$ \\
\hline Types of purchase behavior & $0.38(29,93.49 \%)$ & $0.45(39,93.13 \%)$ & $0.55(1,85.92 \%)$ \\
\hline Purchase intention & $0.38(19,94.48 \%)$ & $0.44(24,94.25 \%)$ & \\
\hline Purchase attitude & $0.39(18,92.23 \%)$ & $0.48(20,92.69 \%)$ & \\
\hline Purchase decision & & $0.43(5,94.14 \%)$ & \\
\hline Purchase frequency & $0.17(1, \mathrm{NA})$ & $0.40(1, \mathrm{NA})$ & \\
\hline $\begin{array}{l}\text { Willingness to pay a } \\
\text { premium price }\end{array}$ & $0.56(1, \mathrm{NA})$ & $0.26(4,71.84 \%)$ & $0.55(1,85.92 \%)$ \\
\hline Product category & $0.38(29,93.49 \%)$ & $0.45(39,93.13 \%)$ & $0.55(1,85.92 \%)$ \\
\hline Food & $0.38(20,92.5 \%)$ & $0.46(12,95.38 \%)$ & $0.55(1,85.92 \%)$ \\
\hline Non-food & $0.42(8,95.56 \%)$ & $0.43(16,88.73 \%)$ & \\
\hline Non-specific products & $0.18(1, \mathrm{NA})$ & $0.45(11,93.9 \%)$ & \\
\hline Country development level & $0.38(29,93.49 \%)$ & $0.45(39,93.13 \%)$ & $0.55(1,85.92 \%)$ \\
\hline Developing & $0.43(22,94.12 \%)$ & $0.46(32,92.82 \%)$ & $0.55(1,85.92 \%)$ \\
\hline Developed & $0.22(7,72.21 \%)$ & $0.32(7,91.71 \%)$ & \\
\hline
\end{tabular}

\subsubsection{Country Economic Development Level}

The effect size differed by country's level of economic development. Overall, the effect sizes of the association between health, environmental and ethical concerns and purchase behavior in low- and middle-income countries were stronger than that in higher-income countries.

Of the 29 studies examining the association between health concern and purchase behavior, the overall effect size in low- and middle-income countries was 0.43 . However, the overall effect size in high-income countries was 0.22 . Of the 39 studies investigating the correlation between environmental concern and purchase behavior, the overall effect size in low- and middle-income countries was 0.46 , and 0.32 in high-income countries. The single study examining the effect of ethical concern on customer purchase behavior was conducted in Turkey, a middle-income country. The overall effect size was 0.55.

\subsection{Results of the 50 Articles Not Included in the Meta-Analysis}

\subsubsection{Descriptive Characteristics}

Of the 50 articles not included in the meta-analysis, the trend pattern of annual numbers of publications was consistent with that of 54 studies included in the metaanalysis (Figure $2 b$ ). The association between health, environmental and ethical concerns and purchase behavior fluctuated and did not appear to be related to time. The investigated products in the 50 articles had the same characteristics with that of 54 studies, with 25 focused on food, 10 on non-food products and the remaining 15 studies examining non-specific products (Supplement S2). Additionally, the most investigated food product was organic food and the most studied non-food product was electric vehicles.

The dependent variables applied to represent purchase behavior in the 50 studies were consistent with that of 54 articles, with 24 purchase intention, 12 purchase attitude, 9 purchase decision, 4 purchase frequency and 5 willingness to pay a premium price (Supplement S2). All of these studies used either Likert scale or Likert-type scale to measure purchase behavior and the sample sizes ranged from 101 to 7627 . 
Of the 50 articles, 21 adopted the SEM method, 27 employed the regression method and the remaining 2 used correlation analysis to analyze data (Supplement S2). Questionnaire was the only method employed to collect primary data.

4.4.2. Results of the Association between Health, Environmental and Ethical Concerns and Purchase Behavior

Of the 50 studies that did not report Pearson's $r$ or were not able to compute Pearson's $r$, 25 investigated the association between health concern and customer purchase behavior and reported a regression or pathway coefficient (shortened as coefficient in this section). Of the 25 studies, 21 reported a positive coefficient $(84 \%)$ and only 4 reported a negative coefficient, indicating the overall effect of health concern on customer purchase behavior was positive, which supports the results of the meta-analysis.

Of the 50 studies, 41 examined the association between environmental concern and customer purchase behavior and reported a coefficient. Of these 41 studies, 36 reported a positive coefficient $(90 \%)$ and only 5 reported a negative coefficient, indicating the overall effect of environmental concern on customer purchase behavior was positive, which supports the results of the meta-analysis.

Of the 50 studies, 3 investigated the association between ethical concern and customer purchase behavior, with 2 reporting a positive coefficient $(66.7 \%)$ and 1 reporting a negative coefficient, indicating that ethical concern had an overall positive impact on customer purchase behavior, which also supports the meta-analysis results.

Of the 25 studies that investigated the association between health concern and purchase behavior, 21 studies reported a positive coefficient in purchase intention, purchase attitude, purchase decision, purchase frequency and willingness to pay a premium price, only 2 reported a negative coefficient in purchase attitude and 2 in purchase intention, indicating an overall positive association between health concern and consumer purchase behavior (purchase intention, purchase attitude, purchase decision, purchase frequency and willingness to pay a premium price), which supports the results of the meta-analysis.

Of the 41 studies that examined the association between environmental concern and purchase behavior, 36 studies reported a positive coefficient for customer purchase intention, purchase attitude, purchase decision, purchase frequency and willingness to pay a premium price, suggesting an overall positive correlation between environmental concern and consumer purchase behavior (purchase intention, purchase attitude, purchase decision, purchase frequency and willingness to pay a premium price). Only two studies reported a negative coefficient in purchase attitude, one in purchase intention, one in purchase frequency, and one in willingness to pay a premium price, which also supports the results of the meta-analysis.

Of the three studies that investigated the association between ethical concern and consumer purchase behavior, two found a positive coefficient in purchase attitude and willingness to pay a premium price, and one found a negative coefficient in purchase intention. These results suggest that the overall correlation between ethical concern and consumer purchase behavior is positive, which also supports the results of the metaanalysis.

When looking at the results from the moderator perspective, the results were also consistent with that of 54 studies included in the meta-analysis. With regard to the association between health concern and customer purchase behavior for food products, 3 found a negative coefficient, and the remaining 18 reported a positive coefficient. In terms of the association between health concern and customer purchase behavior for non-specific products, one reported a negative coefficient, and the remaining two reported a positive coefficient. Only one study investigated the association between health concern and customer purchase behavior for non-food products, and reported a positive coefficient. These results were consistent with that in meta-analysis. With regard to the association between environmental concern and consumer purchase behavior, 36 studies found a positive coefficient in food (13), non-food (10) and non-specific products (13), and only 3 articles found a negative coefficient in food products and 2 in non-specific products, which also support 
the results of the meta-analysis. All of the three studies that investigated the correlation between ethical concern and purchase behavior focused on food, and two reported positive coefficients and one reported negative, which also support the results of the meta-analysis.

When it comes to country's level of economic development, four negative coefficients were found in the association between health concern and purchase behavior in lowand middle-income countries, and five in the association between environmental concern and purchase behavior in low- and middle-income countries. As a result, the remaining 43 articles reported a positive coefficient between health and environmental concern and purchase behavior in all countries, which also support the results of the meta-analysis.

\section{Discussion}

\subsection{Summary of Findings}

The findings of the meta-analysis indicate a direct and positive correlation between health, environmental and ethical concern and customer purchasing behavior, with overall effect sizes of $0.38,0.45$ and 0.55 , respectively. Evidence suggests that these associations are moderated by types of products and country's level of economic development, suggesting that contextual factors (e.g., relative wealth, education, and cultural variation) are likely to impact consumer purchasing behavior. This moderating relation has not been explored in previous reviews. The overall effect size of the association between health concern and willingness to pay a premium price had the strongest correlation, followed by purchase attitude and purchase intention, and the purchase frequency had the least correlation with health concern. The overall effect size of the association between environmental concern and purchase attitude was the highest, followed by purchase intention, purchase decision and willingness to pay a premium price, and the lowest was purchase frequency. Ethical concern had a correlation with purchase intention. These results indicate that the health, environmental and ethical concerns have a weaker impact on the actual purchase behavior (i.e., purchase decision) than on non-actual purchase behavior (e.g., purchase attitude and purchase intention).

The number of studies in this area has increased in recent years, with around 70\% published since 2015. However, the association between health, environmental and ethical concerns and purchase behavior did not appear to be related to time. A considerable majority of studies were undertaken in middle-income countries, especially in China, India and Malaysia. The most studied concern for consumer purchasing behavior was environmental, followed by health concern, and then, ethical concern. Approximately 30\% of studies examined the association between both the health and environmental concerns and purchasing behavior. Almost half of the included studies investigated the association between health, environmental and ethical concerns and purchasing behavior concerning food products. Most studies adopted Likert scale or Likert-type scale to measure consumer purchasing behavior, and many employed Structural Equation Models (SEMs) to analyze the data.

Alongside the meta-analysis, we also studied a body of literature that used different statistical coefficients to report the relationship between health, environmental and ethical concerns and consumer purchasing behavior. Since these studies did not report their results using Pearson's r, we were not able to include them in the meta-analysis. However, we considered these additional 50 studies alongside the 54 studies included in our metaanalysis to give breadth to our analysis. The findings showed good agreement; in almost all cases, the direction of the relationships reported was the same as those given in the meta-analysis. This gives additional support to our meta-analysis findings.

\subsection{Relationship to Previous Literature}

To our knowledge, this is the first meta-analysis and narrative review to summarize the impact of health, environmental and ethical concerns on customer purchasing behavior. Previous studies have attempted such a review for health motives and the purchase of organic food (Rana and Paul 2020), the determinants of green purchases (Liobikiene and 
Bernatonienè 2017), consumers' willingness to pay for organic food (Li et al. 2019; Rana and Paul 2017, 2020), words-deeds gaps in the purchase of fair trade products (Kossmann and Gomez-Suarez 2019), interventions targeting conscious determinants of human behavior to reduce the demand for meat (Bianchi et al. 2018; Moreira et al. 2017), or have focused on a specific geographic region, such as purchasing of organic produce by South African consumers (Fynn-Green et al. 2019), green purchase intentions in Indian consumers (Nath et al. 2017), and green purchasing behaviors of Malaysian consumers (Goh and Wahid 2015). So far, none have attempted to integrate all three concerns, for a variety of purchasing behaviors, and with worldwide coverage. Our synthesis of existing studies should provide a firm basis for other researchers to extend the study of the relationships between health, environmental and ethical concerns and customer purchasing behavior.

\subsection{Limitations and Future Research}

However, many additional questions remain and could be addressed in future research work. First, few of the studies reviewed have investigated the association between ethical concern and customer purchasing behavior, indicating future research might focus on this topic. Second, the association between health, environmental and ethical concerns and consumer purchase behavior in non-food products and conducted in high-income countries needs additional empirical evidence. Third, other techniques than SEM methods should be introduced to provide a complete relation between these concerns and consumer purchase decisions. Fourth, statistical spatial data might provide more concise conclusions with respect to the association between health, environmental and ethical concerns and purchase decisions. Fifth, there was a large degree of heterogeneity and moderator analyses did not explain all variability. Sixth, many factors other than health, environmental and ethical concerns, such as the family and social context as well as the ability to access products that are considered healthy, ethical, and sustainable, may also influence purchasing behavior and should be considered in future research. In addition, our research was limited to publications in the English language. Despite these limitations, this study provides valuable evidence regarding the effects that health, environmental and ethical concerns have on customer purchase behavior.

\section{Conclusions}

This meta-analysis and narrative review bring together empirical evidence for the association between health, environmental and ethical concerns and consumer purchase behavior. The results reveal a direct and positive correlation between health, environmental and ethical concern and purchasing behavior, indicating that an increase in health, environmental and ethical concerns will result in a shift of purchasing towards choices indicated by these concerns. However, the association is moderated by factors including types of products (food, non-food and non-specific products) and country's level of economic development. In addition, these concerns have a weaker impact on the actual purchase behavior than on non-actual purchase behavior (e.g., purchase attitude).

Our findings fill the research gaps in the lack consensus on the significance and directionality of the associations between consumer purchasing behavior and their psychological concern for health, the environment and ethics as well as the relative importance of these concerns in determining consumer purchasing behavior. Additionally, this study provides important insights for marketing managers, governmental bodies, policy makers, product producers and retailers to develop interventions intended to promote more responsible consumption. First, the findings may help practitioners to assess and develop intervention strategies aimed at improving consumers' health, or promoting pro-environmental and/or ethical consumer purchasing behavior. Second, policies and marketing strategies can guide consumers to make more responsible consumption choices that are better for the planet and society by improving consumers' health, environmental and ethical concerns. Third, it appears here that consumer concerns over health, environmental issues and ethical consumption are mostly reflected in non-actual purchase behavior, so intervention strategies 
could focus on translating these "good intentions" into actual purchasing decisions. Fourth, the evidence provided here suggests that people may change purchasing decisions for health, environmental and ethical reasons, rather than purely based on price, suggesting that marketing and policy interventions might utilize these concerns alongside or instead of price.

Supplementary Materials: The following are available online at https:/ /www.mdpi.com/article/10 .3390 /socsci10110413/s1, Supplement S1: Search Strategy, Supplement S2: Characteristics of the 50 articles that did not report $r$ or were not able to compute $r$, Supplement S3: References in 50 articles that did not report $r$ or were not able to compute $r$.

Author Contributions: Conceptualization, R.S., A.M.-L., H.W. and W.N.; methodology, R.S., A.M.-L., H.W. and W.N.; writing—original draft preparation, W.N.; writing—review and editing, R.S., A.M.-L., H.W. and W.N.; supervision, R.S.; project administration, R.S.; funding acquisition, R.S. All authors have read and agreed to the published version of the manuscript.

Funding: This research received no external funding.

Conflicts of Interest: The authors declare no conflict of interest.

\section{Notes}

1 Classification of country economics level is based on the document entitled "country classification" published by the World Bank, see http:/ / data.worldbank.org/about/country-classifications (accessed on 7 October 2020).

\section{References}

Abrar, Muhammad, Sajjad Ahmad Baig, Mohsin Bashir, Rizwan Shabbir, and Muhammad Ayub. 2018. Consumer attitude and purchase intention towards organic textile products. Amazonia Investiga 7: 472-85.

Ajzen, Icek. 1991. The theory of planned behavior. Organizational Behavior and Human Decision Processes 50: 179-211. [CrossRef]

Armstrong, Gary, and Philip Kotler. 2016. Marketing: An Introduction, 13th ed. London: Pearson Education.

Augustine, Amelia Alysha, Anneesha Shavira Rindita, and Sharmila Laksmi Muniandy. 2019. Factors influencing the purchase behaviour of sustainable fashion among millennial consumers in Kuala Lumpur. Paper presented at 2nd International Conference on Big Data Technologies, Jinan, China, August 28-30; pp. 330-34.

Basha, Mohamed Bilal, Cordelia Mason, Mohd Farid Shamsudin, Hafezali Iqbal Hussain, and Milad Abdelnabi Salem. 2015. Consumers Attitude towards Organic Food. Procedia Economics and Finance 31: 444-52. [CrossRef]

Basu, Arindam. 2017. How to Conduct Meta-Analysis: A Basic Tutorial. Christchurch: University of Canterbury.

Bianchi, Filippo, Claudia Dorsel, Emma Garnett, Paul Aveyard, and Susan A. Jebb. 2018. Interventions targeting conscious determinants of human behaviour to reduce the demand for meat: A systematic review with qualitative comparative analysis. International Journal of Behavioral Nutrition and Physical Activity 15: 1-25. [CrossRef] [PubMed]

Birch, Dawn, Juliet Memery, and Maheshan De Silva Kanakaratne. 2018. The mindful consumer: Balancing egoistic and altruistic motivations to purchase local food. Journal of Retailing and Consumer Services 40: 221-28. [CrossRef]

Çabuk, Serap, Ceyda Tanrikulu, and Levent Gelibolu. 2014. Understanding organic food consumption: Attitude as a mediator. International Journal of Consumer Studies 38: 337-45. [CrossRef]

Card, Noel A. 2015. Applied Meta-Analysis for Social Science Research. New York: Guilford Press.

Chaudhary, Richa, and Samrat Bisai. 2018. Factors influencing green purchase behavior of millennials in India. Management of Environmental Quality: An International Journal 29: 798-812. [CrossRef]

Chen, Mei-Fang. 2009. Attitude toward organic foods among Taiwanese as related to health consciousness, environmental attitudes, and the mediating effects of a healthy lifestyle. British Food Journal 111: 165-78. [CrossRef]

Chu, Kuo. Ming. 2018. Mediating influences of attitude on internal and external factors influencing consumers' intention to purchase organic foods in China. Sustainability 10: 4690. [CrossRef]

Farías, Pablo. 2019. Determinants of knowledge of personal loans' total costs: How price consciousness, financial literacy, purchase recency and frequency work together. Journal of Business Research 102: 212-19. [CrossRef]

Fynn-Green, Geraldene, Roger B. Mason, and Andrea Giampiccoli. 2019. Factors that influence perceptions and purchasing of organic produce by South African consumers: A literature review. International Journal of Customer Relationship Marketing and Management 10: 61-76. [CrossRef]

Ghvanidze, Sophie, Natalia Velikova, Tim H. Dodd, and Wilna Oldewage-Theron. 2016. Consumers' environmental and ethical consciousness and the use of the related food products information: The role of perceived consumer effectiveness. Appetite 107: 311-22. [CrossRef]

Goh, Yen-Nee, and Nabsiah Abdul Wahid. 2015. A review on green purchase behaviour trend of Malaysian consumers. Asian Social Science 11: 103-10. [CrossRef] 
Heo, Jun, and Sidharth Muralidharan. 2019. What triggers young Millennials to purchase eco-friendly products? The interrelationships among knowledge, perceived consumer effectiveness, and environmental concern. Journal of Marketing Communications 25: 421-37. [CrossRef]

Hoque, Mohammed Ziaul, Md Alam, and Kulsuma Akter Nahid. 2018. Health Consciousness and Its Effect on Perceived Knowledge, and Belief in the Purchase Intent of Liquid Milk: Consumer Insights from an Emerging Market. Foods 7: 150. [CrossRef] [PubMed]

Hsu, Shu-Yen, Chiao-Chen Chang, and Tyrone T. Lin. 2016. An analysis of purchase intentions toward organic food on health consciousness and food safety with/under structural equation modeling. British Food Journal 118: 200-16. [CrossRef]

Hsu, Shu-Yen, Chiao-Chen Chang, and Tyrone T. Lin. 2017. Safety, Sustainability, and Consumers' Perceived Value in Affecting Purchase Intentions toward Organic Food. Paper presented at 2017 IEEE International Conference on Industrial Engineering and Engineering Management (IEEM), Singapore, December 10-13.

Hwang, Jiyoung. 2016. Organic food as self-presentation: The role of psychological motivation in older consumers' purchase intention of organic food. Journal of Retailing and Consumer Services 28: 281-87. [CrossRef]

Jaiswal, Deepak, and Rishi Kant. 2018. Green purchasing behaviour: A conceptual framework and empirical investigation of Indian consumers. Journal of Retailing and Consumer Services 41: 60-69. [CrossRef]

Jin, Jie, Qiuhong Zhao, and Ernesto D. R. Santibanez-Gonzalez. 2020. How Chinese consumers' intentions for purchasing eco-labeled products are influenced by psychological factors. International Journal of Environmental Research and Public Health 17: 265. [CrossRef] [PubMed]

Kim, Soyoung, and Yoo-Kyoung Seock. 2009. Impacts of health and environmental consciousness on young female consumers' attitude towards and purchase of natural beauty products. International Journal of Consumer Studies 33: 627-38. [CrossRef]

Kimenju, Simon Chege, and Hugo De Groote. 2008. Consumer willingness to pay for genetically modified food in Kenya. Agricultural Economics 38: 35-46. [CrossRef]

Kirmani, Mohd Danish, and Mohammed Naved Khan. 2018. Decoding willingness of Indian consumers to pay a premium on green products. South Asian Journal of Business Studies 7: 73-90. [CrossRef]

Konuk, Faruk Anıl. 2018. Antecedents of pregnant women's purchase intentions and willingness to pay a premium for organic food. British Food Journal 120: 1561-73. [CrossRef]

Konuk, Faruk Anil. 2019. Consumers' willingness to buy and willingness to pay for fair trade food: The influence of consciousness for fair consumption, environmental concern, trust and innovativeness. Food Research International 120: 141-47.

Kossmann, Elena, and Monica Gomez-Suarez. 2019. Words-Deeds Gap for the Purchase of Fairtrade Products: A Systematic Literature Review. Frontiers in Psychology 10: 2705. [CrossRef] [PubMed]

Kouy, Sothea, Parichard Sangkumchaliangb, and Satit Adittoc. 2016. Consumers' attitude and intention to purchase organic goods in Cambodia. International Journal of Business 21: 328-41.

Kuhar, Ales, and Luka Juvancic. 2010. Determinants of Purchasing Behaviour for Organic and Integrated Fruits and Vegetables in Slovenia. Agricultural Economics Review 11: 70-83.

Lee, Seahee. 2011. Consumers' value, environmental consciousness, and willingness to pay more toward green-apparel products. Journal of Global Fashion Marketing 2: 161-69. [CrossRef]

Lee, Hyun-Joo. 2016. Individual and Situational Determinants of U.S. Consumers' Buying Behavior of Organic Foods. Journal of International Food and Agribusiness Marketing 28: 117-31. [CrossRef]

Li, Rui, Hsiu-Yu Lee, Yu-Ting Lin, Chih-Wei Liu, and Prony F. Tsai. 2019. Consumers' willingness to pay for organic foods in China: Bibliometric review for an emerging literature. International Journal of Environmental Research and Public Health 16: 1713. [CrossRef] [PubMed]

Li, Zhihong, Yongzhong Sha, Xuping Song, Kehu Yang, Kun ZHao, Zhixin Jiang, and Qingxia Zhang. 2020. Impact of risk perception on customer purchase behavior: A meta-analysis. Journal of Business \& Industrial Marketing 35: 76-96.

Liao, Xianchun, Shiran Victoria Shen, and Xunpeng Shi. 2020. The effects of behavioral intention on the choice to purchase energysaving appliances in China: The role of environmental attitude, concern, and perceived psychological benefits in shaping intention. Energy Efficiency 13: 33-49. [CrossRef]

Lin, Pei-Chun, and Yi-Hsuan Huang. 2012. The influence factors on choice behavior regarding green products based on the theory of consumption values. Journal of Cleaner Production 22: 11-18. [CrossRef]

Liobikiene, Genovaite, and Jurga Bernatonienè. 2017. Why determinants of green purchase cannot be treated equally? The case of green cosmetics: Literature review. Journal of Cleaner Production 162: 109-20. [CrossRef]

Magnusson, Maria K., Anne Arvola, Ulla-Kaisa Koivisto Hursti, Lars Åberg, and Per-Olow Sjödén. 2003. Choice of organic foods is related to perceived consequences for human health and to environmentally friendly behaviour. Appetite 40: 109-17. [CrossRef]

Malik, Muhammad Imran, Faisal Nawaz Mir, Saddam Hussain, Shabir Hyder, Asim Anwar, Zia Ullah Khan, Noman Nawab, Syed Farjad Ali Shah, and Muhammad Waseem. 2019. Contradictory results on environmental concern while re-visiting green purchase awareness and behavior. Asia Pacific Journal of Innovation and Entrepreneurship 13: 17-28. [CrossRef]

Marzuki, Sharifah Zannierah Syed, Roslilee Ab Halim, Zulkifli Ab Ghani Hilmi, and Maisarah Ishak. 2017. Structural equation modeling for healthy food products purchase intentions. Advanced Science Letters 23: 3097-101. [CrossRef]

Michaelidou, Nina, and Louise M. Hassan. 2008. The role of health consciousness, food safety concern and ethical identity on attitudes and intentions towards organic food. International Journal of Consumer Studies 32: 163-70. [CrossRef] 
Michaelidou, Nina, and Louise M. Hassan. 2010. Modeling the factors affecting rural consumers' purchase of organic and free-range produce: A case study of consumers' from the Island of Arran in Scotland, UK. Food Policy 35: 130-39. [CrossRef]

Mishal, Aditi, Rameshwar Dubey, Omprakash K. Gupta, and Zongwei Luo. 2017. Dynamics of environmental consciousness and green purchase behaviour: An empirical study. International Journal of Climate Change Strategies and Management 9: 682-706. [CrossRef]

Moreira, Sheillam Moreira, Leandro Costa, Gladiscorrea Corrêa de Conto, Revista Eudu Bom Schwengber, Vaz Zach, and Silveira Barbosa-Isabella. 2017. Beef: Consumer Perceptions front of the animal welfare-Review. Revista Electronica de Veterinaria 18: 1-17.

Murray, Jennifer M., Sarah F. Brennan, David P. French, Christopher C. Patterson, Frank Kee, and Ruth F. Hunter. 2017. Effectiveness of physical activity interventions in achieving behaviour change maintenance in young and middle-aged adults: A systematic review and meta-analysis. Social Science E Medicine 192: 125-33.

Nath, Vishnu, Rajat Agrawal, Aditya Gautam, and Vinay Sharma. 2017. Antecedents of green purchase intentions: A review and testing of hypothesis on Indian consumers. International Journal of Environment and Sustainable Development 16: 297-314. [CrossRef]

Nawi, Noorshella Che, Abdullah Al Mamun, Nurul Hasliana Binti Hamsani, and Mohd Nazri bin Muhayiddin. 2019. Effect of Consumer Demographics and Risk Factors on Online Purchase Behaviour in Malaysia. Societies 9: 10. [CrossRef]

Ng, Mark, Monica Law, and Serene Zhang. 2018. Predicting purchase intention of electric vehicles in Hong Kong. Australasian Marketing Journal 26: 272-80. [CrossRef]

Nguyen, Phuong Ngoc Duy, Vinh Tan Nguyen, and Nguyen Ngoc Thao Vo. 2019. Key determinants of repurchase intention toward organic cosmetics. Journal of Asian Finance, Economics and Business 6: 205-14. [CrossRef]

Nguyen, Ninh, Hoang Viet Nguyen, Phuong Thao Nguyen, Viet Thao Tran, Hoang Nam Nguyen, Thi My Nguyet Nguyen, Tuan Khanh Cao, and Tran Hung Nguyen. 2020. Some key factors affecting consumers' intentions to purchase functional foods: A case study of functional yogurts in Vietnam. Foods 9: 24. [CrossRef] [PubMed]

Pandey, Sanjeev, and Sandeep Srivastava. 2017. A Study on Determinants of Customer Purchase Intention in Healthcare Product-A Case of General Medical Equipment in India. Journal of Management 4: 19-30.

Pino, Giovanni, Alessandro M. Peluso, and Gianluigi Guido. 2012. Determinants of Regular and Occasional Consumers' Intentions to Buy Organic Food. Journal of Consumer Affairs 46: 157-69. [CrossRef]

Polman, Evan, and Kaiyang Wu. 2019. Decision making for others involving risk: A review and meta-analysis. Journal of Economic Psychology 72: 200-18. [CrossRef]

Prakash, Gyan, Pankaj Kumar Singh, and Rambalak Yadav. 2018. Application of consumer style inventory (CSI) to predict young Indian consumer's intention to purchase organic food products. Food Quality and Preference 68: 90-97. [CrossRef]

Rana, Jyoti, and Justin Paul. 2017. Consumer behavior and purchase intention for organic food: A review and research agenda. Journal of Retailing and Consumer Services 38: 157-65. [CrossRef]

Rana, Jyoti, and Justin Paul. 2020. Health motive and the purchase of organic food: A meta-analytic review. International Journal of Consumer Studies 44: 162-71. [CrossRef]

Rashid, Nik Ramli Nik Abdul, and Mohd Rizaimy Shaharudin. 2017. Customer's purchase intention for a green home. International Journal of Procurement Management 10: 581-99. [CrossRef]

Reimers, Vaughan, Bryce Magnuson, and Fred Chao. 2017. Happiness, altruism and the Prius effect: How do they influence consumer attitudes towards environmentally responsible clothing? Journal of Fashion Marketing and Management 21: 115-32. [CrossRef]

Ritter, Ágata M., Miriam Borchardt, Guilherme LR Vaccaro, Giancarlo M. Pereira, and Francieli Almeida. 2015. Motivations for promoting the consumption of green products in an emerging country: Exploring attitudes of Brazilian consumers. Journal of Cleaner Production 106: 507-20. [CrossRef]

Saleki, Reza, Farzana Quoquab, and Jihad Mohammad. 2019. What drives Malaysian consumers' organic food purchase intention? The role of moral norm, self-identity, environmental concern and price consciousness. Journal of Agribusiness in Developing and Emerging Economies 9: 584-603. [CrossRef]

Salimi, Ahmad Reza. 2019. Effects of environmental concerns and green knowledge on green product consumptions with an emphasis on mediating role of perceived behavioural control, perceived value, attitude, and subjective norm. International Transaction Journal of Engineering Management \& Applied Sciences E Technologies 10: 651-61.

Schill, Marie, Delphine Godefroit-Winkel, Mbaye Fall Diallo, and Camilla Barbarossa. 2019. Consumers' intentions to purchase smart home objects: Do environmental issues matter? Ecological Economics 161: 176-85. [CrossRef]

Seyfang, Gill. 2005. Shopping for sustainability: Can sustainable consumption promote ecological citizenship? Environmental Politics 14: 290-306. [CrossRef]

Shukla, Sadhna. 2019. A Study on Millennial Purchase Intention of Green Products in India: Applying Extended Theory of Planned Behavior Model. Journal of Asia-Pacific Business 20: 322-50. [CrossRef]

Smith, Samantha, and Angela Paladino. 2010. Eating clean and green? Investigating consumer motivations towards the purchase of organic food. Australasian Marketing Journal 18: 93-104. [CrossRef]

Sriram, Mahadevan. 2018. Determinants of RoE of S\&P BSE Sensex Companies: A Panel Data Analysis. Indian Journal of Finance 12: $56-65$.

Sriwaranun, Yaowarat, Christopher Gan, Minsoo Lee, and David A. Cohen. 2015. Consumers' willingness to pay for organic products in Thailand. International Journal of Social Economics 42: 480-510. [CrossRef]

Suki, Norazah Mohd. 2013. Green awareness effects on consumers' purchasing decision: Some insights from Malaysia. International Journal of Asia-Pacific Studies 9: 49-63. 
Sumi, Razia Sultana, and Golam Kabir. 2018. Factors affecting the buying intention of organic tea consumers of Bangladesh. Journal of Open Innovation: Technology, Market, and Complexity 4: 24. [CrossRef]

Svecova, Jana, and Pavla Odehnalova. 2019. The determinants of consumer behaviour of students from Brno when purchasing organic food. Review of Economic Perspectives 19: 49-64. [CrossRef]

Tan, Christine Nya Ling, Adedapo Oluwaseyi Ojo, and Ramayah Thurasamy. 2019. Determinants of green product buying decision among young consumers in Malaysia. Young Consumers 20: 121-137. [CrossRef]

Testa, Francesco, Silvia Sarti, and Marco Frey. 2019. Are green consumers really green? Exploring the factors behind the actual consumption of organic food products. Business Strategy and the Environment 28: 327-38. [CrossRef]

Thananusak, Trin, Sirisuhk Rakthin, Thiti Tavewatanaphan, and Prattana Punnakitikashem. 2017. Factors affecting the intention to buy electric vehicles: Empirical evidence from Thailand. International Journal of Electric and Hybrid Vehicles 9: 361-81. [CrossRef]

Tong, Gia-Tuong, and Gi-Du Kang. 2019. Important factors that affect vietnamese consumers' green purchasing behavior. International Journal of Innovative Technology and Exploring Engineering 8: 474-78.

Uzdavinyte, Elze, Martin Aubel, and Justina Gineikienè. 2019. It is domestic, it must be healthy: How health consciousness and consumer ethnocentrism shape healthiness perception and purchase intentions of domestic food. Organizations and Markets in Emerging Economies 10: 196-211. [CrossRef]

Viswanathan, Meera, Nancy D. Berkman, Donna M. Dryden, and Lisa Hartling. 2013. Assessing Risk of Bias and Confounding in Observational Studies of Interventions or Exposures: Further Development of the RTI Item Bank; Rockville: Agency for Healthcare Research and Quality. Available online: https:/ /www.ncbi.nlm.nih.gov/books/NBK154461/ (accessed on 7 October 2021).

Voon, Thomas Jan P., Kwang Sing Ngui, and Anand Agrawal. 2011. Determinants of Willingness to Purchase Organic Food: An Exploratory Study Using Structural Equation Modeling. International Food and Agribusiness Management Review 14: 103-20.

Wang, Shanyong, Jin Fan, Dingtao Zhao, Shu Yang, and Yuanguang Fu. 2016. Predicting consumers' intention to adopt hybrid electric vehicles: Using an extended version of the theory of planned behavior model. Transportation 43: 123-43, Studies included in the primary meta-analysi. [CrossRef]

Wang, Xuhui, Frida Pacho, Jia Liu, and Redempta Kajungiro. 2019. Factors Influencing Organic Food Purchase Intention in Developing Countries and the Moderating Role of Knowledge. Sustainability 11: 209. [CrossRef]

Wang, Jianming, Thuy Linh Pham, and Van Thac Dang. 2020. Environmental consciousness and organic food purchase intention: A moderated mediation model of perceived food quality and price sensitivity. International Journal of Environmental Research and Public Health 17: 850. [CrossRef] [PubMed]

Wu Jinnan, Fang Wang, Lin Liu, and Donghee Shin. 2020. Effect of Online Product Presentation on the Purchase Intention of Wearable Devices: The Role of Mental Imagery and Individualism-Collectivism. Frontiers in Psychology 11: 56.

$\mathrm{Xu}$, Xiaoping, Shanyong Wang, and Yugang Yu. 2020. Consumer's intention to purchase green furniture: Do health consciousness and environmental awareness matter? Science of the Total Environment 704: 135275. [CrossRef] [PubMed]

Yadav, Rambalak, and Govind Swaroop Pathak. 2016a. Intention to purchase organic food among young consumers: Evidences from a developing nation. Appetite 96: 122-28. [CrossRef] [PubMed]

Yadav, Rambalak, and Govind Swaroop Pathak. 2016b. Young consumers' intention towards buying green products in a developing nation: Extending the theory of planned behavior. Journal of Cleaner Production 135: 732-39. [CrossRef]

Yazar, Evrim Erdoğan, and Murat Burucuoglu. 2019. Consumer Attitude towards Organic Foods: A Multigroup Analysis across Genders. Istanbul Business Research 48: 176-96.

Yogananda Auroomooga, Putten Yuviraj, and Praveen Balakrishnan Nair. 2019. Green food product purchase intention: Factors influencing Malaysian consumers. Pertanika Journal of Social Sciences and Humanities 27: 1131-44.

Yoo, Jeong-Ju, Lorynn Divita, and Hye-Young Kim. 2013. Environmental awareness on bamboo product purchase intentions: Do consumption values impact green consumption? International Journal of Fashion Design, Technology and Education 6: 27-34. [CrossRef]

Zhang Biao, Zetian Fu, Jian Huang, Jieqiong Wang, Shuyao Xu, and Lingxian Zhang. 2018. Consumers' perceptions, purchase intention, and willingness to pay a premium price for safe vegetables: A case study of Beijing, China. Journal of Cleaner Production 197: 1498-507. [CrossRef] 